\title{
Pedagogía y Didáctica de la Corporeidad. Una mirada desde la praxis Pedagogy and Didactics of Corporeality. A look from praxis
}

\author{
Jayson Bernate \\ Corporacion Universitaria Minuto de Dios (Colombia)
}

\begin{abstract}
Resumen. Los desafíos actuales que enfrenta el sector educativo con respecto a las expectativas y retos que demanda la sociedad en el siglo XXI, requieren de una formación de docentes comprometidos con un cambio social en su práctica pedagógica, maestrosque transformen su quehacer con propuestas innovadorasen sus didácticas, con un carácter emprendedor, creativos, críticos, competentes en esta cultural digital que nos avasalla día a día, con liderazgo social, con un grado óptimo de bienestar emocional y, en este sentido, se requiere un cambio significativo en el rol del docente, basado en aprendizajes colaborativos que permitan al estudiante construir su propio conocimiento desde una estrecha relación entre familia, escuela y comunidad, ya que la educación es responsabilidad de toda la sociedad y no meramente de los entes institucionales, escuela 0 universidad. Con esta sistematización reflexiva del ejercicio docente se pretende socializar el aporte significativo de la corporeidad en la pedagogía moderna y como esta aporta en el ejercicio docente pràxico y didáctico, transformando la sociedad mecanicistapostmodernistasumergidaen losámbitostecnológicosalejándose del concepto de cuerpo y su articulación en los procesos de expansión del conocimiento.
\end{abstract}

Palabras clave: Expresión corporal; corporeidad; pedagogía; educación, didáctica.

\begin{abstract}
The current challenges facing the educational sector with respect to the expectations and challenges that society demands in the 21st century requirethe training of teachers committed to social change in their pedagogical practice, teachers who transform their work with innovative proposals in their didactic, with an entrepreneurial character, creative, critical, competent in this digital culture that overwhelms us day by day, with social leadership, with an optimal degree of emotional well-being and, in this sense, a significant change in the role of the teacher is required, based on collaborative learning that allows the student to build their own knowledge from a close relationship between family, school and community, since education is the responsibility of the whole of society and not merely of institutional entities, school or university. With this reflexive systematization of teaching practice, the aim is to socialize the significant contribution of corporeity in modern pedagogy and how it contributes in practical and didactic teaching practice, transforming the postmodernist mechanistic society immersed in technological fields, moving away from the concept of body and its articulation in the processes of expansion of knowledge.
\end{abstract}

Keywords: Body expression; corporeity; pedagogy; education, didactics.

\section{Introducción}

En esta continua transformación de paradigmas educativos, cabe pensar en la misma transformación del docente en formación. No solo apuntando a las tecnologías sino al saber de su práctica docente con miras a fortalecer los procesos de formación que atañan al desa rrollo creativo, que aprenda y desaprenda en cada momento, con mentalidad flexible, que pueda adaptarse a un mundo tan complejo, tan cambiante y contradictorio.

En la pedagogía, abordada como una ciencia que estudia la formación, remite a un interrogante esencial para intentar determinar de qué forma aprenden los

\footnotetext{
Fecha recepción: 28-12-20. Fecha de aceptación: 05-03-21 Jayson Bernate

jayson.bernate@ uniminuto.edu
}

seres humanos. Así mismo, como arte de la educación, intenta descubrir las potencialidades del proceso educa tivo en beneficio de un aprendizaje integral y para toda la vida. 0 tros autores la definen como una disciplina del saber, con su propio objeto de estudio y, de esta forma, la abordan como el saber que estudia los procesos educativos, cuyo fundamento filosófico es la formación referida al proceso de enseñanza-aprendizaje. (Bernate et al., 2019)

En este sentido anotaM ontenegro (2005) que el dispositivo que hace la diferencia entre los estratos sociales y económicos es la calidad de la educación ya que se identifica desigualdad social con desigual dad de oportunidades educativas. Por lo tanto, es de vital importancia mitigar esta gran diferencia con una educación de calidad sin el tinte de clase social, por constituirse en un derecho, una práctica social que responde a una visión de hombre generada por la sociedad. De ahí que los 
procesos de formación que se establecen, deben enfocarse a la cal idad de los docentes, ofreciendo a sus estudiantes no solo contenidos impactantes, novedosos y de alta calidad, sino también procesos de retroalimentación con otros docentes para mejorar sus prácticas docentes, lo que comúnmente se ha señalado como comunidades de aprendizaje. También como lo recomienda Rico (2016)

La gestión de procesos de formación docente es necesario en cualquier institución con miras a tener una educación con calidad, y no solo eso, la exigencia del mercado hace que las universidades además de tener excelente infraestructura, requieren que se le otorgue valor a la labor de los docentes, no solo de tipo económico, también, valor a la labor del profesor es garantizar las oportunidades de su profesionalización, forma ción y desempeño dentro de la universidad, de esta forma, se está ahondado en las necesidades del grupo docente y abarcando las necesidades de la institución y su meta de al canzar una educación de calidad. (p. 58)

De otro lado, Freire (2006) hace referencia a la autonomía como la principal esencia del quehacer docente, que implica ser el mediador entre los procesos de enseñanza y aprendizaje, creando en el aula un ámbito de confianza que involucre creatividad y experticia en su disciplina. Esto conlleva a que el docente se repiense en su actuar desde una reflexión y mejora continua. Aludiendo a las diferentes posturas de la conceptualización de práctica pedagógica, el autor enfatiza en el componente de transformación social que implica nuestra ta rea educadora. Consideremos pues la impronta que ca racteriza a U NIM INUTO dentro de su enfoque social, que la devela con un fuerte compromiso con una sociedad de jóvenes que lleguen a cumplir con su proyecto de vida donde los docentes fomentan la autodisciplina, autonomía y formación en valores.

Teniendo en cuenta lo anterior, el rol del maestro debe resignificarse y es primordial que se comprometa a cambiar la manera de mediar el conocimiento y el modo de ofrecerlo a los estudiantes, reflexionar sobre la función social del saber desde una mediación pedagógica donde el estudiante viene a ser el protagonista de este escenario en una estrecha relación dialéctica entre el conocimiento, las nuevas tecnologías de la informa ción y la cultura. En esta reflexión aparecen unos cuestionamientos sobre el quehacer docente que cada uno responderá en su interior, entre éstos ¿Están los docentes en capacidad de asumir los nuevos retos tecnológicos que pueden contribuir a la práctica pedagógica?, ¿Será que la educación tradicional continúa presen- te en nuestro quehacer?, ¿Para qué enseñar?

En primera instancia, es primordial redimensionar el concepto de práctica pedagógica, el cual encierra el significado de interactuar con otras personas dedicadas a articular, planear, examinar, asumir y posibilitar proyectos. Por consiguiente, la práctica docente no contiene una reflexión por sí misma y, en este sentido, como afirma Betancourt (2013) «al mismo tiempo que se ejerce 0 se realiza dicha práctica pedagógica no se produce la pedagogía como formación discursiva, teoría o reflexión sobre ella, como condición ineludible de su ejercicio» (p. 95). Por ende, se entiende que la práctica docente debe articularse con el diálogo y la reflexión sobreel quehacer pedagógico, resolviendo dificultadesque se presentan en el ejercicio de enseñanza-aprendizaje.

En el contexto del aula no es extraño reconocer que las prácticas en su mayor parte giran alrededor del maestro, quien utiliza el discurso pedagógico, cuyo pretexto son los contenidos que le permiten mediar el conocimiento. Sin embargo, actualmente se continúa con esas prácticas tradicionalistas, dando importancia a la instrucción, dejando de lado aquellos aprendizajes que se fundan en la crítica y la reflexión. Como lo sustenta Ramírez (2020)

Lainnovación educativa aparece como un tema pendiente en las agendas de las instituciones educativas a nivel internacional. Las políticas educativas vigentes ponen de manifiesto la importancia de la innovación educativa como un elemento clave para la mejora de la calidad educativa y el desarrollo social. (p. 2)

En este sentido y desde los estudios de Guazamayán (2000) se aportan valiosos aspectos sobre los propósitos que debe tener una práctica docente o pedagógica en la búsqueda de un profesional idóneo frente a las necesida des socioculturales de los estudiantes. Así plantea la importanciade unaformación integral que conlleve unas competencias básicas adecuadas al quehacer docente ta les como: interpretar, argumentar y proponer acciones pedagógicas en las que el estudiante debe comprometerse con la planeación, gestión y ejecución de proyectos de investigación, en el marco de una cultura ciuda dana. Basados en la idea de 0 spina (2013)

Por tanto, los continuos cambios sociales que experimenta la sociedad se reflejan en los comportamientos de los ciudadanos, ya sean adultos o menores, y en las dinámicas de los centros e instituciones educativas, cuyo microsistema absorbe la diversidad y complejidad del microsistema social. Los educadores, el profesorado y los centros e instituciones educativas se enfrentan, en el momento actual, al reto de ofrecer respuesta a la am- 
plia demanda educativa de la sociedad contemporánea. (p. 169)

Desde esta perspectiva, preguntarse por el cuerpo es un tema de actualidad, que empieza a tener su propio lugar de enunciación. Desde la Educación Física se estudian sus relaciones con el sujeto y todas sus posibilidades expresivas y comunicativas, y no solo se hace referencia al cuidado del cuerpo en términos de bienestar y salud. Por el contrario, el cuerpo habla permanentemente de todo lo que le acontece cotidianamente, lo cual hace que se generen unas relaciones sujeto-cuerpo que responden a una visión integral. Para ello Gómez et al. (2018) recomiendan:

Reconocer la dimensión simbólica del cuerpo en la educación es comprender que él anuncia las formas de experiencia con el mundo y con sí mismo, de esta ma nera, el lenguaje poético del cuerpo es sentido, sensa ción, afección, percepción, pasión, voluntad y deseo y puede afirmarse que el cuerpo es el lugar de la irrupción del acontecer. (p.189)

Por otro lado, actualmente el Ministerio de Educa ción Nacional -MEN sugiere dentro de sus documentos de trabajo las O rientaciones Pedagógicas para la Educa ción Física, Recreación y Deporte, las cuales constituyen la propuesta curricular del enfoque de desarrollo de competencias donde la corporeidad toma un papel relevante en los procesos de formación. La corporeidad entendida como el ente mediador y las respectivas relaciones que se dan entre el conocimiento, el mundo que lo rodea y su integración con la naturaleza. Asimismo, esatravés del cuerpo quese experimentaunaamplia relación con el movimiento, la emoción y los sentidos. «Las emociones determinan constantemente el comportamiento humano, por lo que estas no pueden desvincularse del ámbito educativo, siendo la educación emocional necesaria para el desarrollo integral de los alumnos/ as» (Bermúdez \& Sáenz, 2019, p. 597).

En consecuencia, tendrían que repensarse las didácticas específicas de la Educación Física, para que no se aborde solo desde el entrenamiento de las capacida desmotoras, sino desde una pedagogía de lacorporeidad. Por eso es primordial retomar el papel protagónico del docente, revisando su propio cuerpo, su propia forma ción corporal, sus prácticas y cómo éstas se vinculan a la cultura. Hay un interés creciente por procesos de formación donde el cuerpo sea asumido desde manifesta ciones corporales que a través de la experiencia provoquen cambios de actitud hacia el reconocimiento de sí mismo y de los límites corporales que impone el mundo actual. En ese sentido Castro et al. (2013) orientan hacia la concepción didáctica como:

La concepción al rededor del campo conceptual de la didáctica se ha debatido entre dos perspectivas, una de ellas propone la didáctica como una disciplina autónoma en su construcción teórica, y otraquela determinacomo la aplicación de técnicas educativas que materializan las concepciones pedagógicas y formativas, es decir, la didáctica hace parte de la pedagogía, la pedagogía está inmersa en la formación y la formación está determina da por la sociedad. Es por esta relación de interdependencia que se concibe la didáctica como una disciplina que permite la materialización de la intencionalidad formativa y pedagógica. (p. 418)

Hay que redimensionar las prácticas corporales hacia la búsqueda del auto-conocimiento, como una alternativa para hacer visible en todos los sujetos el cuidado de sí mismos. Es decir, el cuerpo de cada sujeto tiene un sustento biológico pero cada ser humano, condicionado por su circunstancia y contexto de vida, determinacómo quiere vivir su corporeidad, imaginarla, utilizarla o desarrollarla en determinado sentido. «Estamos convencidos que educar a través de la corporeidad puede contribuir decisivamente a la consecución de estas metas, ayudando a las personas a encontrar el equilibrio y la armonía interna que requiere el acto de vivir con plenitud» (Águila \& López, 2018, p.420).

En la actualidad existe una diversidad de enfoques sobre esta dimensión corporal, que implican diferentes consideraciones y tratamientos del cuerpo que los estudiantes necesitan identificar y definir. Es propósito del futuro docente establecer una conciencia de su propio cuerpo para redimensionar la práctica docente como educador físico. Es necesario construir un nuevo tipo de relación entre la educación, los contenidos, los sujetosy sus cuerpos. Relación que contemple los errores y los aciertos de la Educación Física y que ponga en debate sus actuales límites y sus horizontes. Sobre el tema, Soares (2014) menciona que:

Tal vez el cuerpo, por ser esta tela tan frágil donde la sociedad se proyecta, pueda ser el punto de partida, hoy, para pensar lo humano, para preservar lo humano, este humano factible, inusitado, que guarda siempre un resto de misterio y, así, romper con la auto alienación que hace que la humanidad viva su propia destrucción como un placer estético. (p. 129)

Definitivamente y desde la reflexión del quehacer pedagógico en una Pedagogía del Cuerpo que supone una transformación en las prácticas de los docentes, se anota que el cuerpo puede ser abordado desde la fenomenología, el entrenamiento, el acondicionamien- 
to, modelación y organicidad, entre otros, y como expresan Gallo \& M artínez (2015) «la Educación Física ha olvidado lacorporeidad, lo quees, de al gún modo, mostrar un desprecio por el cuerpo sensible, expresivo, gestual, artístico, creador y creativo»(p.619). En este sentido, la historia de la Educación Física demuestraque esta disciplina ha enseñado el cuerpo-físico en toda su dimensión humana, pero el cuerpo-emocional que constituye al hombre como un sujeto vivo-expresivo, y que lo legitima como ser único con su propia identidad, ha quedado relegado a un segundo plano.

Como educadores físicos es pertinente darse a la tarea de desarrollar la corporeidad desde espacios como la danza y la expresión corporal, logrando integrar el yo-cuerpo que en últimas constituye al sujeto con una representación ante el mundo.

La Educación Física vista y originada como disciplina, propiciaexperiencias demovimiento dondeel cuerpo vivencia prácticas corporales que le permiten afianzar sus capacidades físicas, cognitivas y afectivas procurando como su nombre lo indica educar, formar y tomar conciencia de la responsabilidad que tiene el sujeto para ser activo y saludable durante toda la vida. «La expresión corporal, como materia curricular en la formación de maestros y maestras del itinerario de educación física, se nutre de una historia, didáctica, metodología, conceptualizaciones, dinámicas evaluativas, actividades, propuestas y ejemplificaciones ampliamente mostradas en la literatura» (Prados, 2019, p. 645). Además de hacer transformaciones de tipo social por medio de la educación corporal, respondiendo a las necesidades de la comunidad. Desdeel punto de vistaBernate et al. (2019)

Es necesario que los educadores físicos se apersonen de proyectos para fortalecer a las comunidades en las cuales trabajan. Es necesario que el sector académico se comprometa con el fortalecimiento de la política pública y así facilitar el desarrollo de la infraestructura, asignación de rubros a nivel comunitario regional y na cional que cubran las diferentes necesidades de la sociedad con relación a las diferentes clasificaciones del deporte. (p.746)

De igual manera como proceso educativo, la Educa ción Física es un elemento fundamental de la pedagogía ya que contribuye a desarrollar las cualidades básicas del ser humano en cuanto a su dimensión bio-psico-social, que le permite comprender su propio cuerpo, desde sus posibilidades y limitaciones. En esta medida, la Educación Física de calidad contribuye a aprender a convivir desde el respeto, la autonomía y la valoración de la diversidad cultural del entorno. Si bien es cierto, la
Educación Física no ha mirado el lenguaje de la corporeidad como una unidad de posibilidades expresivas que fortalecen una construcción de sujeto en su total idad. Al hablar de lenguaje corporal no se descarta el lenguaje verbal, ya que ambos se complementan en un proceso de comunicación efectiva; de un lado, se suministra una información verbal y, de otro lado, se confirma, se rechaza o se soporta en los significados de la gestualidad. Como lo sustentan M uñoz et al. (2009)

Lo extralingüístico se transforma en unaherramienta útil en la enseñanza para la inclusión de todos los estudiantes, considerando que las diversas demandas que exigen los actuales sistemas educativos, ameritan un trabajo creativo, para que desde el Curriculum escolar se generen respuestas a las necesidades que presentan los educandos, brindando la posibilidad de aprovechar al máximo su potencial en la perspectiva de lograr personas más íntegras que puedan desarrollar sus proyectos de vida plenamente, privilegiando la igualdad de oportunidades y estableciendo el aula regular como un espa cio idóneo para cumplir estos fines. (p. 43)

Es de conocimiento que en los lineamientos curriculares del Ministerio de Educación Nacional (MEN) se contempla que dentro de los contenidos de Educación Física se debe incluir el área de Expresión Corporal; sin embargo, son muy pocos los docentes que se atreven a realizar o diseñar una sesión de este tipo, muy seguramente por el desconocimiento o por el miedo que produce salirse del esquema tradicional. Situa ción que lleva a algunos docentes a prescindir de esta sesión (Rojas et al., 2019). La invitación está en no decaer en el intento, se puede apostar a una sesión de clase con una didáctica donde el docente tenga una actitud proactiva, de escucha, de apertura y ante todo que comprenda que el estudiante puede aportar y generar nuevas posibilidades de encuentro consigo mismo, estimulando la creatividad en un ámbito de confianza, reforzando las acciones del grupo y en especial de manera individual con aquellos estudiantes que presenten dificultades de baja autoestima o que se encuentren aisla dos 0 reticentes.

Conviene resaltar que desde la Expresión Corporal se puede educar en la sensibilidad, gozando de una experiencia vital que permite el autoconocimiento, el desarrollo de la auto-imagen, el conocimiento del grupo de compañeros, la desinhibición, etc. En este sentido, laEducación Físicadebe ir másalláde la acción motriz hacia una didáctica de la Expresión Corporal que incluya una liberación que permita expresar las emociones, sentimientos y sensaciones a través del cuerpo. En sen- 
tido coloquial, se señala que las pal abras pueden disfra zar lo que realmente se piensa y se siente, pero el cuerpo lo delata. Así mismo Ros (2003) propone que:

Todos los seres humanos desde que nacemos poseemos la capacidad de expresarnos corporalmente a partir denuestraExpresión Corporal Cotidiana, por lo tanto todos podemos llegar a elaborar nuestra propia manera de danzar. De esta conducta, específicamente humana, se desprende la Expresión Corporal-Danza, como lenguaje extra verbal y también es desde toman sus bases diferentes disciplinas artísticas como las que involucran al mimo, al clown, al actor. Todas estas manifestaciones artísticas tienen en común la corporización y traducción en mensajes corporales organizados, de los movimientos internos psíquicos o sea lo relacionado con el pensamiento, las imágenes, los afectos, las emociones, las fantasías. (p. 9)

Ahora bien, al escalar la propuesta de Expresión Corporal en el programa de Licenciatura en Educación Física, Recreación y Deporte, se observa que el espa cio académico de Expresión Corporal está enmarcado en el principio teórico de Stokoe (2005) citado por Cáceres (2010) quien fundamenta lo siguiente;

Laesferacorporal, constituyeuna conductaqueexiste desde siempre en todo ser humano. Es un lenguaje preverbal, extra verbal y paralingüístico por medio del cual el ser humano se expresa a través de sí mismo, reuniendo en su cuerpo el mensaje y el canal, el contenido y la forma, pues él es cuero y no tiene cuerpo.( p.2)

Con respecto a lo anterior se puede observar que la Expresión Corporal es un lenguaje no verbal de natura leza universal que permite que el cuerpo a través y por medio del movimiento se exprese, se haga presente y se comunique consigo mismo y entre en relación con los demás, con códigos corporales como los gestos, la postura, la manera en que se mueve, para hacer presencia en el mundo. Por consiguiente, el cuerpo está en continuo movimiento así esté estático; paradójicamente, se escucha muy poco al cuerpo, a pesar de que existimos a partir y desde la corporeidad.

Sobre este campo, un término acuñado por Stokoe (1997) citado por Galo (s.f) es la Expresión CorporalDanza, definido como la danza creativa al alcance de todos, concepto de danza libre referido a la búsqueda de posibilidades y limitaciones expresivas tanto de sí mismo como de los demás para canalizar y liberar energías desde el movimiento que le ha sido innato pero que en su propia historia ha sido relegado a un segundo plano, para así reencontrarse consigo mismo en un proceso de auto reconocimiento. Lo cual confirma la relevancia de abordar desde la primera infancia y más aún como futuros docentes, la educación del cuerpo y la expresión, dada su influencia en la formación de mejores seres humanos. Por tal motivo Blanco (2009) afirma que:

De esta forma, el niño construye su expresión corporal, a través de maestros expresivos y generadores deambientes de aprendizaje significativos. Contemplándolo como un actor social, quien le dasignificado al quehacer pedagógico y didáctico para trasformar los espacios. Se requiere un trato desde el afecto y el respeto a través de la expresión ar tística, la expresión del cuerpo y el lenguaje para desarrollar su amor propio. (p. 22)

Asimismo, en la construcción de formador de formadores, laexperienciavividadelosestudiantescambia no solo en su perspectiva conceptual sino en la posibilidad del encuentro consigo mismo desde el reconocimiento de su lenguaje corporal. «Para que el ser humano tenga una formación integral es necesario tener un diseño curricular robusto, que se plantee con las necesidades del contexto y tenga relación con los procesos de formación» (Betancourt et al., 2020, p. 848). De tal manera, que en el buen sentido de esta concepción de cuerpo y desde lo motriz, la corporeidad es un contenido clave para repensar la Educación Física, dado que, no solo como disciplina del saber sino en su proceso de formación, tiene que dar cuenta de la integralidad del ser humano (Bernate et al., 2019).

Pese a que hoy en día el cuerpo está siendo violenta do, mutilado, con cicatrices de una guerra constante, no solo como resultado de la situación misma del conflicto armado, sino por el incremento permanente de acciones violentas que agreden el cuerpo (Bernate $\&$ Vargas, 2020). Al respecto, es pertinente que la Educación Física genere retos de transformación social que conlleven un cambio desde las didácticas, para humanizar las prácticas deportivas de alto rendimiento, hacer más cerca na la recreación como una forma de sentirse bien, educar para el tiempo libre y el ocio, poner en práctica la rehabilitación a partir de lo humano, lo sensible y lo perceptivo, contribuyendo así a la formación de ese ser integral, capaz de equilibrar las tensiones ocasionadas por el estrés de este mundo tan diverso y cambiante. Lo cual, supone a su vez, una transformación en la formación docente y en sus prácticas pedagógicas. De ahí que los currículos deben generar una perspectiva desde lo humano, permeada por una pedagogía del cuerpo y de la corporeidad, contemplando en toda su esencia, al ser humano (U rrea et al., 2018).

De acuerdo a lo anteriormente sustentado esta sistematización de experiencias pedagógicas se plantea 
social izar y sistematizar ejercicios metodológicos en fases del modelo pedagógico que trabaja la institución analizada.

\section{Metodología}

En tal sentido, la sistematización posee los rasgos, procesos y resultados que dan cuenta de una metodología de investigación cualitativa. Así mismo, al querer definir sistematización de experiencias, se debe suscribir a «un ejercicio que está referido, necesariamente, a experiencias prácticas concretas» (Jara, 1994, p. 17). En ese sentido el autor afirma que: Se entiende la sistema tización como un proceso permanente, acumulativo, de creación de conocimientos a partir de nuestra experiencia de intervención en una realidad social, como un primer nivel de teorización sobre la práctica. Desde aquí, la sistematización representa una articulación entre teoría y práctica... y sirve a objetivos de los dos campos. Por un lado, apunta a mejorar la práctica, la intervención, desde lo que ella misma nos enseña... de otra parte... , aspira a enriquecer, confrontar y modificar el conocimiento teórico actualmente existente, contribuyendo a convertirlo en una herramienta realmente útil para entender y transformar nuestra propia realidad (1994, p. 20).

\section{Participantes}

La sistematización de esta experiencia pedagógica estuvo conformada por los estudiantes de segundo semestre de Licenciatura en Educación de la Corporacion Univer sitaria M inuto de Dios UN IM INUTO sede principal, de la ciudad de Bogotá-Colombia.

\section{Instrumento}

El instrumento utilizado en esta sistematización de experiencia fue la guía de sistematización de experiencias pedagógicas del modelo pedagógico institucional de la Corporación U niversitaria Minuto de Dios propuesto por (Juliao, 2007). El cual se divide en 4 categorías:

Fase del Ver: Esta es una fase de exploración y de análisis/ síntesis(VER) que respondealapregunta: ¿Q ué sucede?; etapa fundamentalmente cognitiva donde el profesional/ praxiólogico que recoge, analiza y sintetiza la información sobre su práctica profesional, tratando de comprender su problemáticay de sensibilizarse frente a ella (Juliao, 2007, p.87).

Fase del Juzgar: Esta es la fase de reacción (JUZGAR) que responde a la pregunta ¿qué puede hacerse?; etapa fundamentalmente hermenéutica en la que el profesional/ praxiólogo examina otras formas de enfocar la problemática de la práctica, visualiza y juzga diversas teorías, de modo que pueda comprender la práctica, conformar un punto de vista propio y desarrollar la empatía requerida para participar y comprometerse con ella. (Juliao, 2007. p. 88)

Fase del Actuar: la fase del actuar que responde a la pregunta ¿Q ué hacemos en concreto?, etapa fundamentalmente programática en la que el profesional/ praxiólogo construye, en el tiempo y el espacio de la práctica, la gestión finalizada y dirigida de los procedimientos y tácticas previamente validados por la experiencia y planteados como paradigmas operativos de la acción. (Juliao, 2007. p. 88)

Fase de Devolución Creativa: La reflexión en la acción (DEVOLUCIÓN CREATIVA), etapa fundamental mente prospectiva que responde a la pregunta: ¿Q ué aprendemos de lo que hacemos? La prospectiva es una representación que pretende orientar el proyecto y la práctica del profesional/ praxiólogo; una representación donde el futuro es planteado a priori como un ideal. (Juliao, 2007. p. 89)

\section{Procedimiento}

Para la sistematización de la experiencia pedagógica, se informó a los jóvenes de segundo semestre de la Licenciatura acerca de la naturaleza de la sistematización y sus fases, se solicitó la colaboración de las directivas de la Facultad de Educación. Se entregó un formato de autorización dirigido a los estudiantes, solicitando su consentimiento para la participación en la sistematiza ción de experiencia. Se desarrollaron 8 sesiones de actividad física regulada mediante el espacio académico de Expresión Corporal durante 50 minutos cada una, desde allí se registraron y analizaron las guías de sistematización de experiencias pedagógicas en sus cuatro fases.

\section{Resultados y Discusión}

De acuerdo ala experiencia vivida en la Corporacion Universitaria M inuto de Dios U NIM INUTO desde los espacios académicos de Expresión Corporal y atendiendo los desafíos que implica abanderar la docencia en donde la educación es el motor que puede llegar a contribuir a la reconstrucción de tejido social, el perfil de formación de futuros docentes que contiene un sello particular de responsabilidad social que lo diferencia de otros, debe estar encaminado a la construcción de una pedagogía de la paz en la que el cuerpo sea el primer territorio de paz. Bajo esta filosofía Silvera \& Huertas 


\section{(2018) sustentan que:}

Las tendencias y tensiones que se dan, entre el entretejido de las relaciones y conexiones sociales, permiten la construcción de una estructura funcional entre el maestro, el estudiante y la sociedad que permite la subsistencia de valores y principios capaces de llegar a definir el rumbo de la vida social y comunitaria en el Estado Social de Derecho. (p. 148)

Essabido que, a lo largo de estos 50 años de conflicto armado, las narrativas de la violencia han sido relatadas desde los cuerpos mutilados, maltratados y silenciados, en donde se está experimentando una corporeidad atemorizada que excluye al otro por sus temores y miedos, que implica un acto violento cualquiera que fuese en mayor o menor rango y que en la mayoría de los casos, causa dolor. El superar estos rastros violentos implica una nueva manera de mirar el mundo desde acciones de paz, que, en este caso, conformarían las didácticas dela pedagogíadelacorporeidad, ya que como lo proponen Castro et al., (2013) «se constituye como una representación simbólica de la realidad educativa ubicada siempre desde un paradigma histórico determinado que tiene por objetivo bajar a la realidad educa tiva las construcciones conceptuales y reproducir idealmente el proceso enseñanza-aprendizaje»(p.416).

En medio de tantas heridas sociales se estaría apostando a la formación de la corporeidad como estrategia de resiliencia, con la capacidad para adaptarse y superar la adversidad, sanar y aliviar a partir de la Expresión Corporal. En esta perspectiva, los estudiantes que llegan a este espacio académico difieren en la mayor parte del conocimiento que implicalaexpresión corporal dentro de la Educación Física. En sus primeras clases se delata una incertidumbre de los contenidos programáticos y experiencias a vivir que contemplan su propio cuerpo. No ha existido anteriormente otro espacio académico que les permita explorar su vocabulario corporal (M oreno \& Pérez, 2013). Por lo tanto, a medida que transcurren las sesiones de clase se genera un ámbito de aprendizaje de confianza, de conocimiento tanto a nivel teórico y práctico, basado en la realización de ciertos ejercicios expresivos propuestos, donde cada uno experimenta un encuentro personal que le permite en primera instancia, atreverse, es decir, mirarse así mismo, y de esta manera ser reconocido por el grupo. Basado en los planteamientos Gonzales \& Gonzales (2010) de «La forma de incorporar la educa ción corporal y motriz en loscurrículos deberíaser transversal y no limitada a una asignatura que siga teniendo como objetivo primordial: el rendimiento, la disciplina y la competencia» (p. 183).

En un sentido amplio, son sesiones de encuentro permanente con su propio yo. Se parte del complejo significado del que emana la expresión, entendida como la representación materializada de una idea, mediante recursos como el habla, la escritura y el lenguaje corporal. (Bernate et al. 2019) En estas tres dimensiones se recorre toda una práctica corporal-expresiva referida a la interiorización de la actitud anímica y emocional que cada uno experimenta. En este contexto, el estudiante expresa sus diferentes modos de pensar, sentir y explorar usando los distintos lenguajes expresivos que dan forma a sus ideas a través de descripciones, relatos, narraciones y diálogos. «En perspectiva fenomenológica, la corporeidad es el concepto clave desde el cual se ha construido esa forma de ordenamiento del conocimiento denominada M otricidad Humana» (Hurtado, 2008, p. 122).

En este transcurrir de diferentes formas expresivas, el estudiante va adquiriendo técnicas que le permiten realizar un trabajo de senso-percepción, entendidacomo el eje de la expresión corporal donde entra en escena, no solo el conocimiento, sino la sensibilización y la conciencia corporal, desarrollando al mismo tiempo la capacidad de observación, el placer por el juego, la improvisación, la espontaneidad y la creatividad. «El proceso perceptivo es el mecanismo sensorio-cognitivo de gran complejidad mediante el cual el ser humano siente, selecciona, organiza e interpreta los estímulos, con el fin de adaptarlos mejor a sus niveles de comprensión» (Vilatuña et al., 2012, p. 128).

El primer encuentro con su propia timidez es la realización de ejercicios de expresión facial que junto con la mirada son los medios más eficaces para expresar emociones y sentimientos. La mirada ejerce un gran poder dentro de la comunicación no verbal. Bien dicen en el acervo popular que la mirada dice más que mil palabras, lo que significa que a través de la mirada podemos ver el interior de las personas. En este sentido, la mira da que en principio rehúyen al gunos, se convierte en la fuerza de poder comunicante a medida que van descubriendo su potencial expresivo-corporal (Bernate et al., 2020).

A lo largo del curso de Expresión Corporal, lo más significativo es la construcción de un ámbito de reconocimiento de sí mismo y del otro; de igual manera se arriesgan a interpretar situaciones de la vida cotidiana desde un vocabulario corporal muy elemental, permitiendo crear imágenes corporales que en cier ta medida los identifican en su realidad y, por consiguiente, su bús- 
queda per sonal adquiere sentido. «Las nuevas disoluciones de las fronteras entre el arte y la vida, proponen un nuevo modo de relacionarse consigo mismo y con los otros, un modo de percibir y producir que dan cuenta una transformación de la experiencia subjetiva» (Yutzis, 2010, p.9).

Seguidamente se acude a los diferentes tipos de lenguaje expresivo como son la danza creativa y la expresión dramática, con el objetivo de exteriorizar desde sus propios sentires temas de su cotidianidad. Así se rea liza un trabajo colaborativo de representación e interpretación. Experimentan diversos ejercicios de expresión dramática donde la creatividad se pone a la orden de la imaginación. Como lo hace notar Gonzales (2015)

Distintas experiencias revelan que los jóvenes, a tra vés del juego dramático, acaban descubriendo el «mila gro» de la creación colectiva, el potencial creador del grupo manifestado en el juego y la aceptación de sus propias capacidades, van rompiendo bloqueos de aquello que se creían incapaces de hacer. (p. 112)

U na vez alcanzado el nivel expresivo se realiza una puesta en común de sus productos artísticos, argumentado desde sus propias miradas del mundo, con un ca rácter artístico y de estética del movimiento. En este orden, realizan sketch de monólogos, de mimos, de danza creativa, de títeres, de marionetas y de juegos dramáticos, ya que el drama es una constante de la vida cotidiana, todo esto permeado por un ejercicio escritural de reflexión de su vivencia en ese ámbito de aprendiza je como educador físico en formación (Bernate et al., 2020).

Dentro del proceso de aula, hay una constante retroalimentación tanto grupal como individual, con el ánimo de fortalecer su experiencia y sus códigos corporales y expresivos. Finalmente hay que destacar el valor social que conlleva este espacio como proceso de formación ya que bien se sabe que el docente debe ser un agente socializador que genere ambientes de aprendizaje en donde la confianza, la libertad, la autonomía, el respeto y el reconocimiento, sean los pilares de forma ción efectiva y eficaz (Bernate et al., 2020). En esta misma dirección el juego simbólico pone de manifiesto la capacidad lúdica y de integración social, que invita a gozar educativamente de una comunicación afectiva que permite continuar la construcción de mejores seres humanos.

En este marco, hay que aprender a exteriorizar las emociones desde una totalidad expresivo-corporal, a hacer del tacto y el con-tacto, los protagonistas de una comunicación auténticay asertiva. En definitiva, hay que tener presente que el verdadero aprendizaje es el que se realiza a través de la experiencia; sólo después de haberla vivenciado, se podrá transmitir (Fonseca et al., 2019).

\section{Conclusiones}

Se debe trabajar imperantemente desde las escuelas e instituciones educativas de educación formales y No formales; para transformar los discursos tradiciona listas y más aún sus prácticas corporales, convirtiéndolos en discursos privilegiados del cuerpo y estereotipos culturales establecidos, enmarcados en la praxis pedagógica del aula, articulando las prácticas a las cuales se sumergen los actores educativos de la sociedad, bajo técnicas de control y conciencia kinestésica-corporal.

El ejercicio pedagógico desde el aula debe romper el paradigma de educar bajo el modelo conductista, el cual irrumpe en el desarrollo expresivo-corporal de los seres humanos; mutilando la libertad de expresión en el aula y fuera de ella y limitando el conocimiento social y cultural.

El mayor reto de esta época digital en que está sumergida la sociedad; para los docentes, se convierte en como atacar y dirimir todas las problemáticas corpora les que se están viviendo hoy en día, desde la población infantil hasta la el adulto mayor, como lo son; la obesidad, enfermedades no trasmisibles, timidez, vicios posturales, etc. Por talesmotivos, el educador físico debe convertir el aula en un espacio de socialización corporal, a través del cuerpo en movimiento solucionando estas problemáticas de tipo corporal.

Con base a los beneficios de la actividad física por medio de la Expresión Corporal, estos pueden provocar cambios en la personalidad, entre ellos, se encuentra una estabilidad emocional, aumento de la euforia y la autoestima, evita agresiones propias, hay alivio emocional evitando la tensión o el estrés, para luego tener una percepción de sí mismo.

\section{Referencias}

Águila Soto, C. , \& López Vargas, J. (2018). Cuerpo, corporeidad y educación: una mirada reflexiva desde la Educación Física (Body, corporeity and education: a reflexive view from Physical Education). Retos, 0(35), 413-421. Recuperado de https:/ / recyt. fecyt. es/ index. php/ retos/ article/ view/ 62035/ 41748

BermúdezTorres, C., \& Sáenz-López, P. (2019). Emociones en Educación Física. Una revisión bibliográfica (2015- 
2017) (Emotions in Physical Education. A bibliographic review (2015-2017)). Retos, 36(36), 597-603. Recuperado de https: / / recyt. fecyt.es/ index. php/ retos/ article/ view/ 70447

Bernđe, J., Bejarano, B., \& Cardozo, D. (2020). Cotejo de las competencias ciudadanas en estudiantes de Licencia tura en Educación Física. Mendive. Revista de Educación, 18(3), 647-660.

Bernate, J., Fonseca, I., Guataquira, A., \& Perilla, A. (2020). Competencias Digitales en estudiantes de Licenciatura en Educación Física (Digital Competences in Bachelor of Physical Education students). Retos, (41), 310-318. https:/ / doi. org/ 10.47197/ retos. V0i41.85852

Bernate, J., Fonseca, I., Jiménez, M. J. B., \& Romero, E. (2020). Análisis de las competencias ciudadanas en estudiantes de Licenciatura en Educación Física. PODIU M: Revista de Ciencia y Tecnología en la Cultura Física, 15(2), 202-220.

Bernđe, J. A., Fonseca, E. R., \& Cruz, J. E. L. (2020). Sedentarismo y actividad física: Revisión bibliográfica de estrategias desde la educación física y aplicaciones prácticas para niños y adolescentes. EmásF, Revista Digital de Educación Físca, 12(67).

Bernđe, J., García-Celis, M., Fonseca-Franco, I., \& RamírezRamírez, N. (2020). Prácticas de enseñanza y evalua ción en una facultad de educación colombiana. Revista de Investigación, Desarrolloelnnovación, 10(2), 337-347. https:/ / doi.org/ 10.19053/ 20278306.v10.n2.2020.10721

Bernate, J., Guataquira, A., Rodríguez, J., Fonseca, I., Rodríguez, M., \& Betancourt, M. (2020). Impacto aca démico y profesional de un programa de educación físicaanivel universitario (Academic and professional impact of university physical education program). Retos, (39), 509-515. https:/ / doi.org/ 10.47197/ retos. v0i39.81087

Bernate, J., Fonseca, I., \& Betancourt, M. (2019). Impacto de la actividad física y la práctica deportiva en el contexto social de la educación superior (Impact of physical activity and sports practice in the social context of higher education). Retos, 37(37), 742-747. https:/ / doi.org/ 10.47197/ retos. v37i37.67875

Bernate, J. Fonseca, I. Betancourt, M. García, F. \& Sabogal, H. (2019) Competenciasciudadanasen laeducación física escolar. Revista Acción Motriz, Asociación Científico Cultural en Actividad Física y Deporte (ACCAFIDE) Las Palmas de Gran Canaria, 23(2), 90- 99. Recuperado de: http:// ww w. accionmotriz. com/ documentos/ revistas/ articulos/23_12.pdf

Bernate, J., Fonseca, I. \& C astillo, E. (2019) Impacto social del deporte y la actividad física en el ámbito escolar. ATH LOS Revista Internacional de Ciencias Sociales de la Actividad Física, el Juego y el Deporte International Journal of
Social Sciences of Physical Activity, Game and Sport (16) 8 7897. https:/ / dialnet. unirioja. es/ servlet/ articulo?codigo $=6837390$

Bernate, J., Fonseca, I., \& U rrea, P. (2019). Impacto en los procesos delainternacionalización y transnacionalización en la educación física superior UNIM INUTO. EmásF: re vista digital de educación físca, (61), 11-23.

Bernate, J., \&Vargas Guativa, J. (2020). Desafíos y tendencias del siglo XXI en la educación superior/ Challenges and trends of the 21st century in higher education. Revista deCienciasSociales, 26, 141-154. Doi:http:/ / dx.doi.org/ 10.31876/ rcs. v26i0.34119

Betancourt, C. (2013). La práctica docente y la realidad en el aula. Revisa Criterios20, 101-118.

Betancourt, M., Bernate, J., Fonseca, I., \& Rodríguez, L. (2020). Revisión documental de estrategias pedagógicas utilizadas en el área de la educación física, paraforta lecer lascompetenciasciudadanas(Documentary review of pedagogical strategies used in the área of physical education to strengthen citizen competenci. Retos, 38(38), 845-851. Recuperado de https: / / recyt.fecyt.es/ index.php/ retos/ article/ view/ 74918/ 49523

Blanco Vega, M. (2009). Enfoques teóricos sobre la expresión corporal como medio de formación y comunicación. Horizontes Pedagógicos, 11(1). Recupera do a partir de https:// horizontespedagogicos ibero. edu.co/ article/ view/ 332 Cáceres, M. (2010). La expresión corporal, el gesto y el movimiento en la edad infantil. Revista digital para profe sonalesdela enseñanza, 9(1), 1-7. Recuperado de: https:/ / www. feandalucia.ccoo.es/ docu/ p5sd7343.pdf

Castro-Carvajal, J., Martínez-Escudero, L., \& Chaverra Fernández, B. (2013). La investigación en pedagogía y didáctica aplicada ala educación física. Educación y Educadores, 15(3), 411-428. Recuperado de https:// educacionyeducadores. unisabana. edu.co/ index. php/ eye/ article/ view/ 2193/ 2953

Fonseca, I., Bernđte, J., Betancourt, M., Barón, B., \& Cobo, J. (2019). Developing Socia Responsibility in U niversity Students. In Proceedings of the 2019 11th International Conference on Education Technology and Computers (ICETC 2019). Association for Computing Machinery, New York, NY, USA, 215-218. Doi: https: / / doi.org/ $10.1145 / 3369255.3369275$

Freire, P. (2006). Pedagogía de la autonomía: saberes necesarios para la práctica educativa. Siglo XXI.

Galo, D. (s.f) Laexpresión corporal-danzaen PatriciaStokoe. Expresión Corporal y Educación. Editorial Deportiva Wanceul en. Recuperado de: http:/ / www.xarnalot.com/ expresiva/ wp-content/ uploads/2015/ 01/ 12-La-ECdanza-en-PatriciaStokoe.pdf 
Gallo, L. E., \& Martínez, L. J. (2015). Líneas pedagógicas paraunaeducacióncorpora. Cadernosdepesquisa, 45(157), 612-629.

Gómez, S.N.; Gallo, L.E.; Planella, J. (2018) Una educa ción poética del cuerpo o de lenguajes estético pedagógicos. Arte, Individuo y Sociedad 30(1), 179-194.

González Correa, Aída María, \& González Correa, Clara Helena (2010). Educación FísicaD esde LaCorporeidad Y La Motricidad. Revisa Hacia la Promoción de la Salud, 15(2), 173-187. [FechadeConsulta12 deM ayo de2020]. ISSN: 0121-7577. Disponible en: https:/ / www. redalyc. org/ articulo. oa?id=3091/ 309126694012

González García, J. (2015). Dramatización y educación emocional. CPU-e, Revista deInvestigación Educativa, 0(21), 98-119. Doi: https:// doi. org/ 10.25009/ cpue. v0i21.1723

Guazamayán, R. \&. (2000). Elementos conceptuales para la formación de Docentes: Centro de Investigaciones para el desarrollo dela Educación y la Pedagogía (GIDEP). San Juan de Pasto, Colombia: Universidad de Nariño.

Hurtado Herrera, Deibar Rene (2008). Corporeidad y M otricidad. Una forma de mirar los saberes del cuerpo. Educação \& Sociedade, 29 (102), 119-136. [fechade Consulta 12 de Mayo de 2020]. ISSN: 0101-7330. Disponible en: https: / / www. redalyc.org/ articulo. oa id $=873 / 87314211007$

Jara, 0. (1994). ParaSistemaizar Experiencias Costa Rica: Publicaciones Alforja. Recuperado de http:/ / ww w. fahce.unlp.edu. ar / extension / Documentos\%20y\%20Ponencias/ parasistematizar-experiencias-una-propuestateorica-y-practica

Juliao, C. (2007). «Educación: unacercamiento praxiológico» en Juliao, C. Educación social. El Minuto de Dios: una experiencia y un modelo. Bogotá: Uniminuto. Disponible en: http:/ / especiales. uniminuto. edu/ file. php/ 1/ Textos/ anexo_1.pdf

Moreno, M. J. C., \& Pérez, M. A. P. (2013). Formación del Profesorado en Expresión Corporal: planes de estudio y Educación Física. Retos: nuevastendenciasen educación física, deporte y recreación, (24), 123-128

Montenegro Armando, R. M. (2005). Las piezas del rompecabezas desigualdad, pobreza y crecimiento. Bogotá: Alfaguara.

Muñoz, MaríaTeresa, González, Carlos, \& Lucero, Boris. (2009). Influencia del lenguaje no verbal (gestos) en la memoria y el aprendizaje de estudiantes con trastornos del desarrollo y discapacidad intelectual: Una revisión. Revista signos, 42 (69), 29-49. https:/ / dx.doi.org/ 10.4067/ S0718-09342009000100002

O spina N ieto, Y. (2013). La pedagogía y su incidencia en la formación de sujetos. Hallazgos, 10(20), 157-170.

Prados Megías, M. (2019). Pensar el cuerpo. De la expre- sión corporal a la conciencia expresivo corporal, un ca mino creativo narrativo en la formación inicial del profesorado (Think the body. From bodily expression to expressive corporal awareness, a narrative creative path in thei. Retos, 37(37), 643-651. Recuperado de https:/ / recyt.fecyt.es/ index. php/ retos/ article/ view/ 74256/ 45771

Ramírez Ramírez, Leticia Nayeli (2020). Tendencias de la innovación educativa en los contextos sociales Análisis del mapeo de literatura Revista Educación, 44(1) ,1-27. [Fecha de Consulta 7 de Abril de 2020]. ISSN : 03797082. Disponible en: https:/ / www. redalyc. org/ articulo. oa?id=440/ 44060092001

Rico,A.D. (2016) Lagestión educativa: Hacialaoptimización de la formación docente en la educación superior en Colombia Sophia 12(1): 55-70.

Rojas, M., Bernđe, J., Fonseca, I. \& \& Betancourt, M. (2019) El método praxeologico como herramienta pedagógica de aprendizaje motriz. ATHLOS Revista Internacional de Ciencias Sociales de la Actividad Física, el Juego y el Deporte International Journal of Social Sciences of Physical Activity, Game and Sport, (18)3, 12-35. Recuperado de: https:/ / dialnet. unirioja.es/ servlet/ articulo?codigo $=7086787$

Ros, N. (2003). Expresión corporal en educación aportes para la formación docente. Revista iberoamericana de educación, 33(2), 1-10.

Silvera Sarmiento, A., \& Huertas Díaz, O. (2018). Resignificación del tejido social, emergente y complejo de laciudadaníaen Colombia Revista EducaciónY Ciudad, (34), 145-156. https: / / doi.org/ 10.36737/ 01230425.v0.n34.2018.1882

Soares, C. L. (2014). Cuerpo e Hisoria. Sao Pablo: Autores Asociados.

U rrea, P., Bernate, J., \& Fonseca, I. (2019). Docentes formadores para la Paz, desde las practicas pedagógicas The Journal of the Latin American Socio-cultural Studies of Sport (ALESDE), 10(1), 92-100. doi:http:/ / dx. doi.org/ 10.5380/ jlasss. v10i1.67594

Vilatuña Correa, Fausto, \& Guajala Agila, Diego, \& Pulamarín, Juan José, \& O rtiz Palacios, Walter (2012). Sensación y percepción en la construcción del conocimiento. Sophia, Colección de Filosofía de la Educación, (13),123-149. [fecha de Consulta 12 de Mayo de 2020]. ISSN : 1390-3861. Disponible en: https:// www. redalyc. org/ articulo. oa?id=4418/441846102006 Yutzis, Daniela (2010). La Expresión Corpora-Danza y los procesos de formación. VI Jornadas de Sociología de la UNLP. Universidad Nacional de La Plata. Facultad de Humanidadesy Ciencias de laEducación. Departamento de Sociología, La Plata. Disponible en: https: / / www. aacademica. org/ 000-027/ 641.pdf 